\title{
Computed tomographic imaging in planning redo cardiac surgery after coronary bypass grafting — a roadmap to safety
}

\author{
T. Smith • M. P. Freericks • W. J. Morshuis
}

Published online: 20 August 2013

(C) The Author(s) 2013. This article is published with open access at Springerlink.com

\section{Introduction}

Patent coronary artery bypass grafts are at risk of injury during redo cardiac surgery. In particular, damage to a patent left internal mammary artery (LIMA) graft during repeat surgery is a well-described and potentially lethal complication [1]. Precise anatomical information is important for planning the surgical approach in reoperative cardiac surgery. The standard preoperative work-up including coronary angiography and chest X-ray may provide unsatisfactory information about the exact anatomical location of grafts [2]. This case report illustrates the value of preoperative computed tomography angiography (CT angiography) in patients undergoing repeat cardiac surgery after prior aortocoronary bypass surgery.

\section{Case}

A 72-year-old male was accepted for redo aortocoronary bypass grafting surgery. He had undergone primary aortocoronary bypass surgery 17 years earlier, with construction of a LIMA to left anterior descending (LAD) graft and a sequential venous graft to the posterolateral territory. Coronary angiography performed because of recurrent chest pain - showed a patent LIMA to LAD graft, and a total occlusion of the venous graft. Furthermore, the proximal course of the LIMA graft seemed to be in close proximity to the sternum (visualised by the sternal

T. Smith $(\bowtie) \cdot$ W. J. Morshuis

Department of Cardiothoracic Surgery, St. Antonius Hospital,

Nieuwegein, PO box 2500, 3430 EM Nieuwegein, the Netherlands

e-mail: t.smith@antoniusziekenhuis.nl

M. P. Freericks

Department of Cardiology, Ikazia Hospital, Rotterdam,

Montessoriweg 1, 3083 AN Rotterdam, the Netherlands wires) (Fig. 1). This finding prompted us to perform CT angiography, confirming the close relationship of the LIMA graft and the posterior table of the sternum; the LIMA was almost adjacent to the sternum and just to the left of the midline over the course of the first two ribs (Fig. 1, image $b$ and c). Just distally from the corpomanubrial junction, the LIMA graft bended posteriorly into the pericardial space (Fig. 1, image d). We decided to perform the repeat median sternotomy slightly to the right of the midline, taking great care not to manipulate the dense adhesive tissue containing the LIMA at the level of the sternal corpus to avoid injury. The LIMA was dissected free in the pericardial space and clamped to facilitate optimal myocardial protection by both antegrade and retrograde cold cardioplegic arrest. At the end of the operation, special care was taken when placing the sternal wires to avoid the region of the LIMA adherence to the sternum. The postoperative course was uneventful.

\section{Discussion}

The risk of injury to a LIMA graft is reported to be as high as $4 \%$ [3], and this risk seems to be directly related to the surgical technique of the primary operation. Several techniques have been described to prevent the LIMA from becoming adherent to the sternum [4-6]. We prefer to route the LIMA into the pericardial cavity through a pericardial incision, anterior and parallel to the phrenic nerve and lateral to the pulmonary artery. For reoperative cardiac surgery after prior aortocoronary bypass grafting, full understanding of the anatomic location of patent grafts is obligatory. Standard work-up including coronary angiography and chest X-ray often fails to provide the cardiac surgeon with adequate anatomical information. Currently, invasive coronary angiography remains the golden standard for assessment of stenosis of both native coronary vessels, and of coronary bypass grafts. 
Fig. 1 Computed tomography and angiography of the LIMA graft. The arrows mark the course of the LIMA graft. The left plane of the figure shows transversal computed tomographic images at different levels: a level of the sternoclavicular joint. $\mathbf{b}$ and $\mathbf{c}$ level of the sternal corpus. d distal from the corpomanubrial junction. e level of the LIMA to LAD anastomosis. The right plane shows the angiographic image of the LIMA graft. LIMA left internal mammary artery, $L A D$ left anterior descending coronary artery

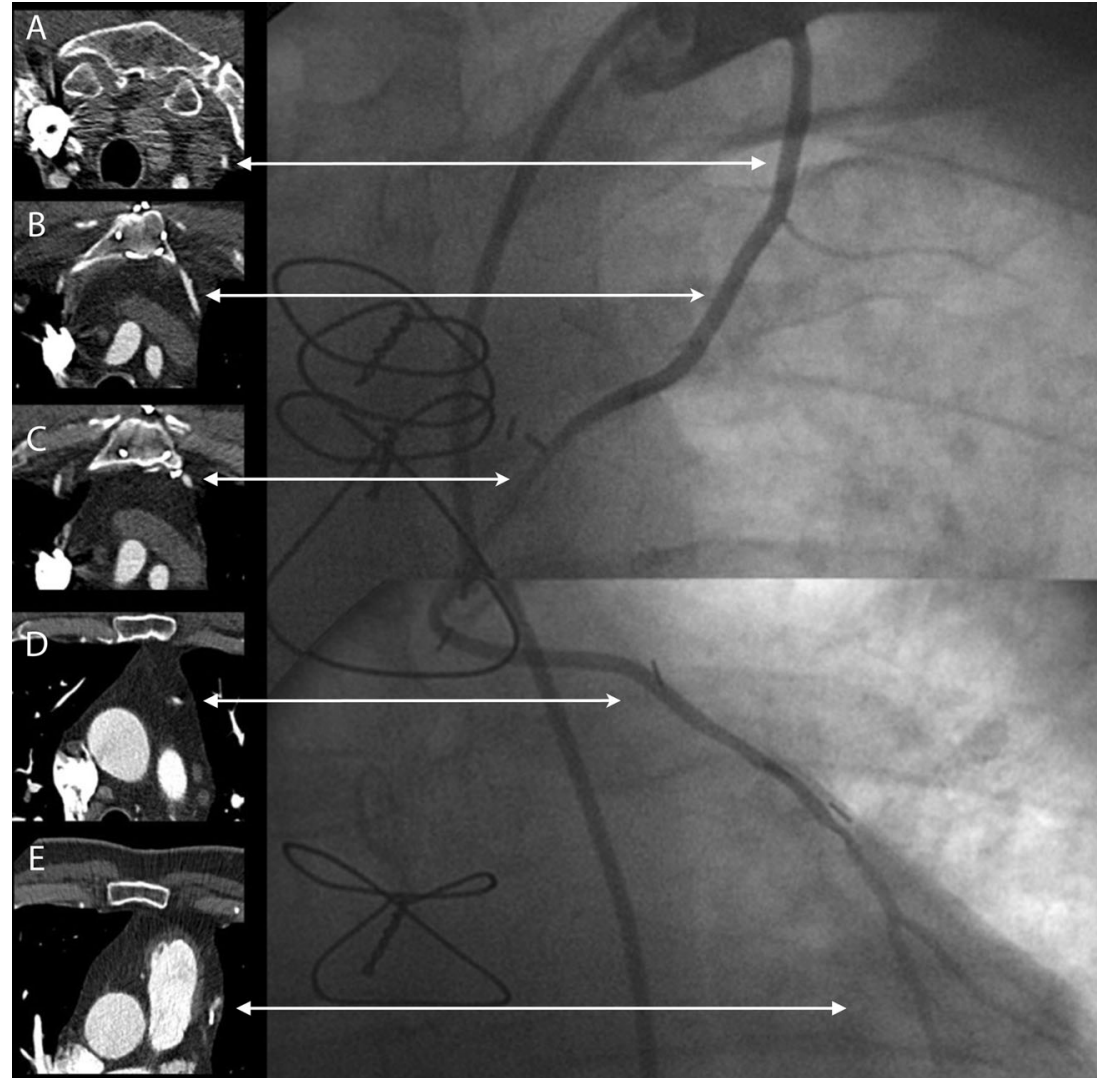

On-going research is providing increasing evidence for the complementary value of CT imaging [7]; recent studies suggest that also the haemodynamic significance of a stenosis may be assessed on CT angiography [8]. Further, evidence on the diagnostic value of CT angiography in detecting significant lesions in coronary bypass grafts is mounting [9]. However, in the present case CT angiography was performed to understand the anatomical relationship of the LIMA graft and the sternum rather than to assess graft patency. In conclusion, this case report illustrates that preoperative CT angiography may provide the surgeon with a 'road map', facilitating safe sternal re-entry, dissection, and sternal closure at the time of reoperation after prior aortocoronary bypass surgery.

\section{Funding None.}

\section{Conflict of interests None declared.}

Open Access This article is distributed under the terms of the Creative Commons Attribution License which permits any use, distribution, and reproduction in any medium, provided the original author(s) and the source are credited.

\section{References}

1. Follis FM, Pett SB, Miller KB, et al. Catastrophic haemorrhage on sternal re-entry: still a dreaded complication? Ann Thorac Surg. 1999;68:2215-9.

2. Aviram G, Sharony R, Kramer A, et al. Modification of surgical planning based on cardiac multidetector computed tomography in reoperative heart surgery. Ann Thorac Surg. 2005;79:589-95.

3. Ellman PI, Smith RL, Girotti ME, et al. Cardiac injury during resternotomy does not affect perioperative mortality. J Am Coll Surg. 2008;206:993-7.

4. Zehr KJ, Lee PC, Poston RS, et al. Protection of the internal mammary artery pedicle with polytetrafluoethylene membrane. J Card Surg. 1993;8:650-5.

5. Pacifico AD, Sears NJ, Burgos C. Harvesting, routing, and anastomosing the left internal mammary artery graft. Ann Thorac Surg. 1986;42:708-10.

6. Berry BE, Davis DJ, Sheely II CH, et al. Protection and expanded use of the left internal mammary artery by pericardial flap technique. J Thorac Cardiovasc Surg. 1988;95:346-50.

7. Weustink AC, de Feyter PJ. The role of multi-slice computed tomography in stable angina management: a current perspective. Neth Heart J. 2011;19:336-43.

8. Meijs F, Cramer MJ, El Aida H, et al. CT fractional flow reserve: the next level in non-invasive cardiac imaging. Neth Heart J. 2012;20:410-8.

9. Șahinera L, Canpolat U, Aytemir K, et al. Diagnostic accuracy of 16versus 64-slice multidetector computed tomography angiography in the evaluation of coronary artery bypass grafts: a comparative study. Interact Cardiovasc Thorac Surg. 2012;15:847-53. 